\title{
A Study on Personnel Safety Evacuation in Underground Commercial Space Based on EXODUS
}

\author{
Lu Ligang \\ School of Safety Engineering \\ China University of Mining and Technology \\ Xuzhou, Jiangsu, China \\ 15262010100@163.com \\ Ji Jingwei \\ School of Safety Engineering \\ China University of Mining and Technology \\ Xuzhou, Jiangsu, China \\ Jjwcn126@126.com
}

\author{
Yang Shaofan \\ School of Safety Engineering \\ China University of Mining and Technology \\ Xuzhou, Jiangsu, China \\ 291685708@qq.com \\ Xie Xinliang \\ School of Safety Engineering \\ China University of Mining and Technology \\ Xuzhou, Jiangsu, China \\ 627742002@qq.com
}

\begin{abstract}
Fire has a high load value and is easy to spread in the underground commercial space. Meanwhile the space has a high occupant density and people in it are difficult to evacuate. So it is easy to cause serious casualties. To this end, this paper first takes a certain underground commercial plaza for example and makes a high-fidelity simulation of dynamic evacuation based on the use of building EXODUS. And then according to the simulation results, it makes evacuation scene design and puts forward three kinds of improvement suggestions. The simulation results shown that the evacuation time is shortened by $7.63 \%, 32.92 \%$ and nearly $15 \%$ respectively and the total evacuation time reduces by nearly $10 \%$. It provides some references for personnel safety evacuation design in underground commercial space. Of course, there is still room for further optimization of the evacuation design. But this optimization design should be synchronized with architectural design based on architectural structure, convenience, economy and normalization.
\end{abstract}

Keywords-underground commercial space;personnel safety evacuation;simulation;EXODUS;improvement suggestions

\section{INTRODUCTION}

Because city becomes more and more prosperous and crowded, the buildings in cities extend from ground space to underground space. As a available form of underground structures, the underground commercial space plays an important role in the development and utilization of underground large space. Underground commercial spaces generally are crowded places with large scale, enclosed system, a few security exits and high crowd density in the internal passages. Meanwhile commodities and interior decorating materials in the underground commercial space are mostly combustible with high fire load and long afterglow time. So, in the event of fire, the heat and smoke is hard to exhaust. It will take place that temperature of the scene of fire gets higher, the toxic gases form and lighting condition gets bad and will make evacuation difficult. Even without fire, as a result of other disasters or false alarm, it is likely to cause crowded people and stampede accidents and will have more serious consequences than it in the ground building[1]. So the research on evacuation problems of underground commercial space gets more and more attention by people[2-8]. Hao Shuqing's Study on Evacuation during Fire in Underground Space Based on Risk Theory and EXODUS taked advantage of building EXODUS to simulate fire accident in underground space and optimizes structure of tunnel[2]. Yin Mingming's Research on the Fire Protection and Evacuation of Underground Commercial Space taked Tianjin Cultural Center underground traffic hub project commercial space as an example, analysed some problems about fire evacuation on the large flat layer of underground commercial space and puts forward some relative feasible project[3]. Wu Xianchao's Analysis on the occupants evacuation time computation of the subway platform Occupant evaluated evacuation time from a station platform by code and by building EXODUS and discussed the security of calculating RSET by simulation software in the performance-based design[4]. Yu Fei's Thoughts on Fire Protection Design of Underground Commercial Space Building proposed some considerations on the fire protection design of underground commercial space building[5].

To this end, this paper describes a process of evacuation simulation for a underground shopping mall by using the high-fidelity dynamic software - building EXODUS. From this, it puts forward the some corresponding improvement suggestions aiming at decreasing the safety evacuation time in the underground commercial space.

\section{BASIC INFORMATION OF THE SHOPPING MALL}

The research object of this paper is a commercial building composed of three underground floors and five ground ones. The first underground floor of the construction is major commodities trade center mainly composed of the shops in central and northern area, department stores in northwest area, the supermarket in northeast area and parking lot in southern area. The gross area of the floor is $71723 \mathrm{~m}^{2}$, with business hall area of 
$45639 \mathrm{~m}^{2}, 36$ fire protection districts and a total of 115 stairs. The width of vast majority of stairs is $2 \mathrm{~m}$. According to the building regulations, it can be figured out that the evacuation width of this floor is $271.55 \mathrm{~m}$. Because of the designed evacuation width of $289.15 \mathrm{~m}$, it satisfies the requirement of safety evacuation.

The first underground floor plan is shown in Fig .1. Due to high flow of people on the first underground floor, this paper directs at evacuation simulation of this floor.

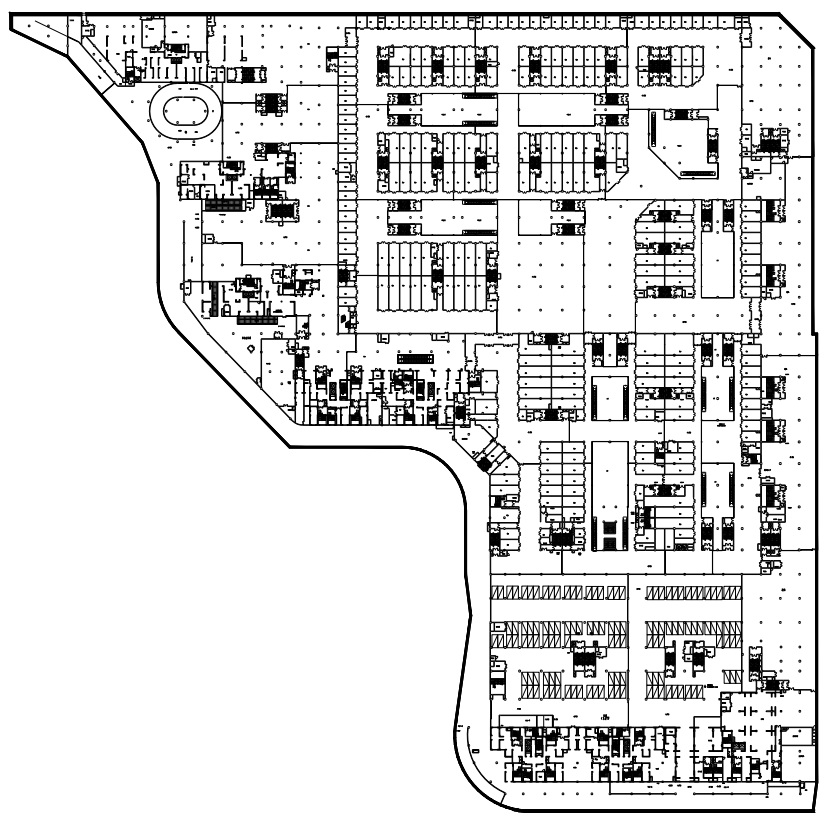

Figure 1. The first plan of underground floor

\section{BUILDING EXODUS OVERVIEW AND EVACUATION SIMULATION OF THE FIRST UNDERGROUND FLOOR}

\section{A. Building EXODUS Overview}

EXODUS is developed by the Fire Safety Engineering Group (FSEG) of the University of Greenwich is a set of software tools which was designed to simulate escape and actions of a large number of individuals in complex buildings. Among them, building EXODUS is a kind of fine-grid evacuation simulation software, considering the interrelations between people, people and fire and people and construction. It can simulate several attributes and behaviors with high fidelity in fire emergency cases and track the evacuation process. "Building EXODUS is designed for applications in the built environment and is suitable for application to supermarkets, hospitals, cinemas, rail stations, airport terminals, high rise buildings, schools etc. Building EXODUS can be used to demonstrate compliance with building codes, evaluate the evacuation capabilities of all types of structures and investigate population movement efficiencies within structures."[9]

\section{B. Related Parameters Settings}

Building construction will be divided into several grids of $0.5 \mathrm{~m} \times 0.5 \mathrm{~m}$ and personnel can move from one grid to the adjacent grid in building EXODUS. Personnel movement speed can be divided into Fast Walk Speed, Walk Speed, Up-Stair Speed and Down-Stair Speed. The specific setting is shown in table 1 .
TABLE I. PERSONNEL SPEED SETTINGS

\begin{tabular}{|c|c|c|c|c|c|}
\hline Sex & Age & $\begin{array}{c}\text { Fast Walk } \\
\text { Speed } \\
{[\mathbf{m} / \mathbf{s}]}\end{array}$ & $\begin{array}{c}\text { Walk } \\
\text { Speed } \\
{[\mathbf{m} / \mathbf{s}]}\end{array}$ & $\begin{array}{c}\text { Up-Stair } \\
\text { Speed } \\
{[\mathbf{m} / \mathbf{s}]}\end{array}$ & $\begin{array}{c}\text { Down-Stair } \\
\text { Speed } \\
{[\mathbf{m} / \mathbf{s}]}\end{array}$ \\
\hline male & $<30$ & 1.5 & 1.35 & 1.01 & 0.67 \\
\hline female & $<30$ & 1.4 & 1.26 & 0.755 & 0.635 \\
\hline male & $30-50$ & 1.35 & 1.215 & 0.86 & 0.63 \\
\hline female & $30-50$ & 1.2 & 1.08 & 0.665 & 0.59 \\
\hline male & $>50$ & 1.15 & 1.035 & 0.67 & 0.51 \\
\hline female & $>50$ & 1.1 & 0.99 & 0.595 & 0.485 \\
\hline
\end{tabular}

According to relevant provision 5.3.17.5 in the Code of Design on Building Fire Protection and Prevention, "the number of evacuating people in stores should be calculated according to construction area of each floor of business hall multiplied by the area converted value and conversion coefficient of evacuating people."[10]

The area converted values in ground stores should be $50 \% \sim 70 \%$ and it in underground stores should not be less than $70 \%$. Conversion coefficients of evacuating people are decided according to Table 5.3.17-2. The following (1) is got:

$$
P(\mathrm{p})=S\left(\mathrm{~m}^{2}\right) \times K \times A\left(\mathrm{p} / \mathrm{m}^{2}\right)
$$

In (1) above, $P$ represents the number of evacuating people, p, here p represents person; $S$ represents business hall construction area, $\mathrm{m}^{2} ; K$ represents the area converted values, constant; $A$ is a conversion coefficient $\left(\mathrm{p} / \mathrm{m}^{2}\right)$.

According to the drawing dimension and related forms in the National Norm of Building Fire System Design, values of $S, K$ and $A$ are 45639, 0.7 and 0.85 , respectively. So it can be easily calculated that $P$ is 27155 by equation above.

For personnel proportion of sex and age, we use the default values of software parameters. Because in the underground mall stairwells are all enclosed stairway, in the process of simulation, it can be seen as that personnel arrive safety area that underground personnel arrived in stair inside. In order to simplify the evacuation process, we will handle the upward stairs directly as a door in the process of parameters settings and the connection number between doors and nodes is decided by the specific width of the stairs.

\section{Result for Evacuation Simulation}

After simulating evacuation of people on this floor by building EXODUS three times, it is found that three simulation processes and results are similar. In this will be subject to one simulation process, the situation of personnel movement in the process of simulation is shown in Fig .2, evacuation flow and the total number of evacuation with the change of time are shown in Fig .3.

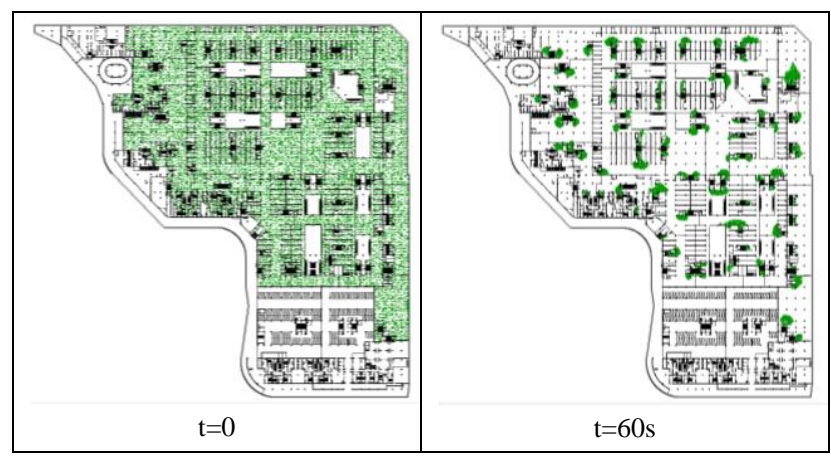




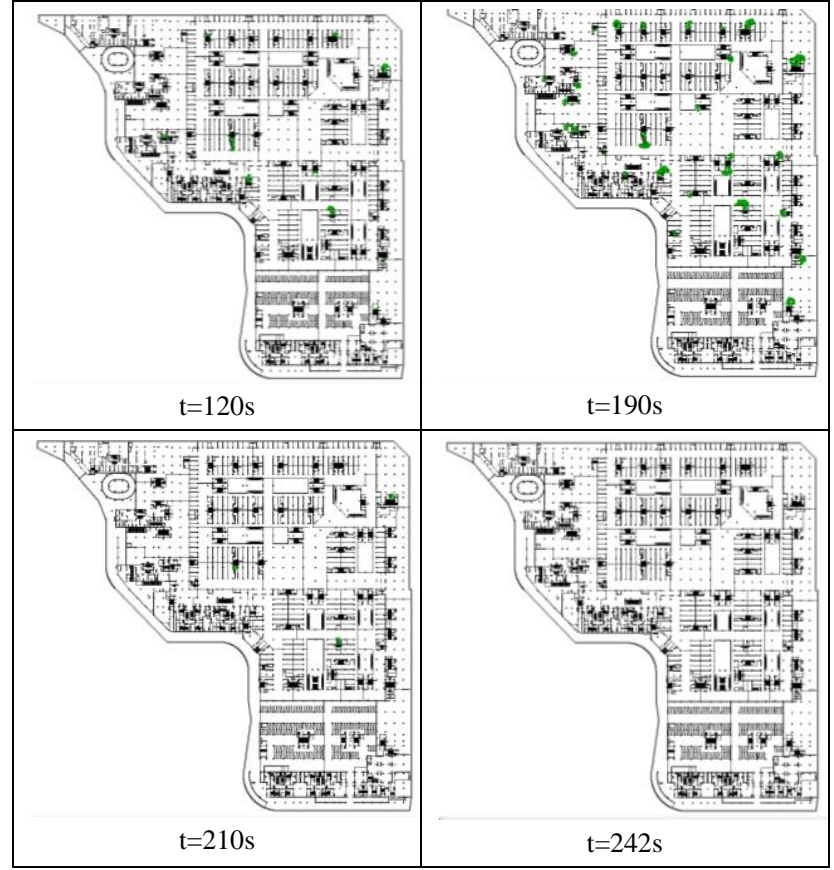

Figure 2. Simulation in the process of evacuation

Total Flow Rate 5.0 (occ/s) X10

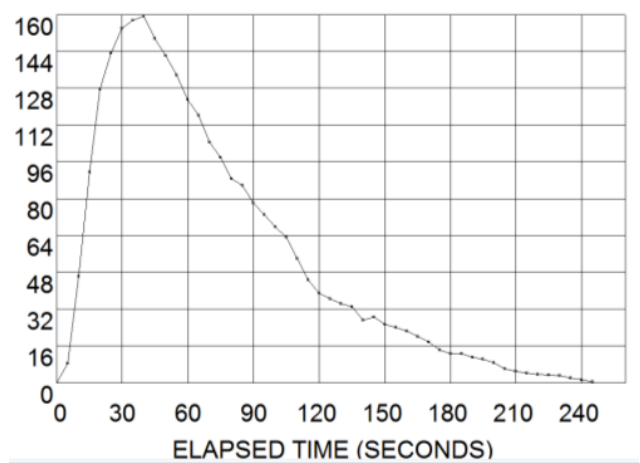

(a)

PEOPLE X100

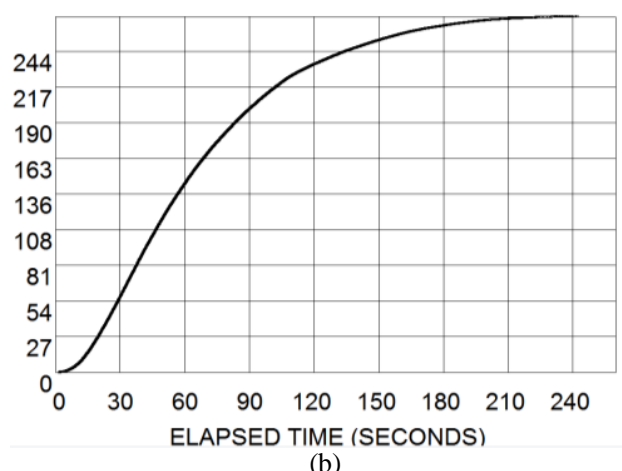

(b)

Figure 3. Total evacuation flow rate (a) and the total number of evacuation (b) with the change of time

The simulation results show that the time needed for that all people evacuate to stairs is $242.3 \mathrm{~s}$.

At 40 s, the maximum evacuation flow rate appears and people evacuate to the staircases with the fastest speed. After 40s, because of the situation that people at the entrances of staircases get crowded and lead to the decrease of evacuation flow rate, it seriously hinders the evacuation and delays the evacuation time. Based on the simulation, the used time and evacuation flow rate that everyone gets to each enclosed stairway can be got. The time that last person taken to enter the stair is $242.3 \mathrm{~s}$.

At $\mathrm{t}=210 \mathrm{~s}$ from the evacuation simulation diagram as seen in Fig .4 below, it can be seen that the time taken to evacuate in stairs at position 1 located in the northeast supermarket and stairs at position 2 and position 3 located in the central business district is longer than other it in other stairs. The research can make optimization design for the four stairs for typical to shorten the evacuation time.

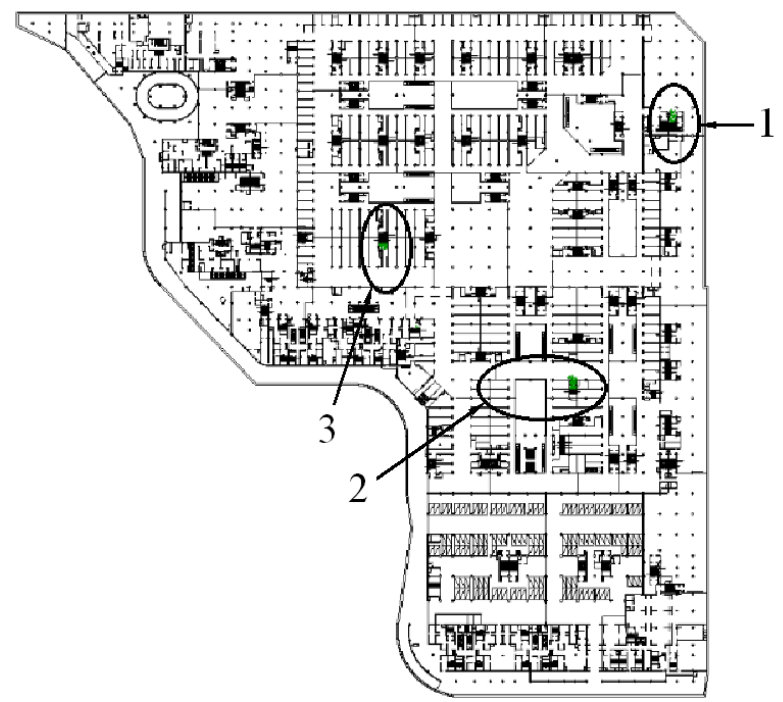

Figure 4. Personnel distribution when the evacuation time is $210 \mathrm{~s}$

\section{IMPROVEMENT SUGGESTIONS}

In order to guarantee that safe passage can fit the requirements of the evacuation, it is necessary to strengthen reservation control for stairs and ground entrances and exits for the underground commercial space. It is important to make the space planning reasonable and refine the design on structure and function, especially for area that people daily are concentrated.

In this section, according to the results of building EXODUS, we use different methods separately to make structure optimization for the four typical stairs above mentioned which cost more time in the process of evacuation. In general, there are three ways to achieve the goal as follows.

\section{A. Adjusting the Relative Position of Evacuation Exits}

For example, for the two stairs which are marked at position 1 in Fig .4, one of the stairs can be moved to the middle or the north of the supermarket. Before and after the modification, the two plans are shown below in Fig .5. 


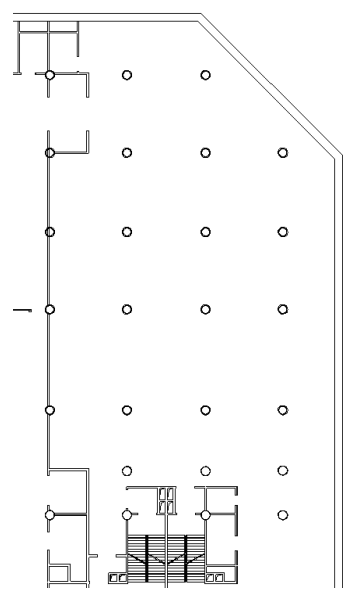

(a)

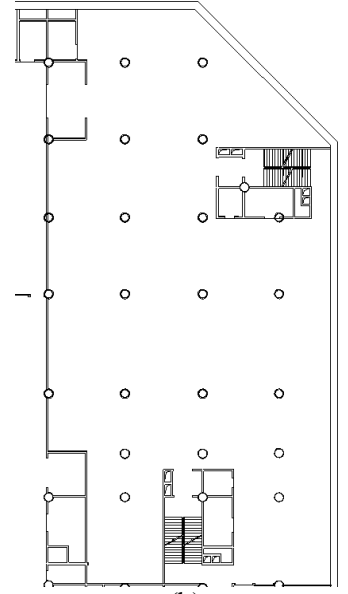

(b)
Figure 5. Detailed comparison before(a) and after(b) change of the relative position of the two stairs

\section{B. Adding an Evacuation Staircase}

For example, for the stair at position 2 in central business district, we can be appropriately add a stairwell near the stair as shown in Fig .6.
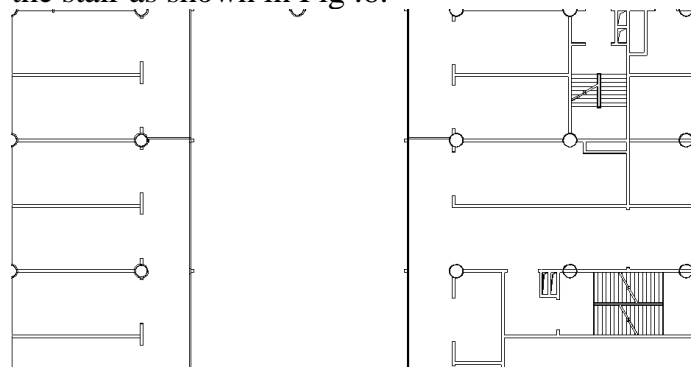

(a)
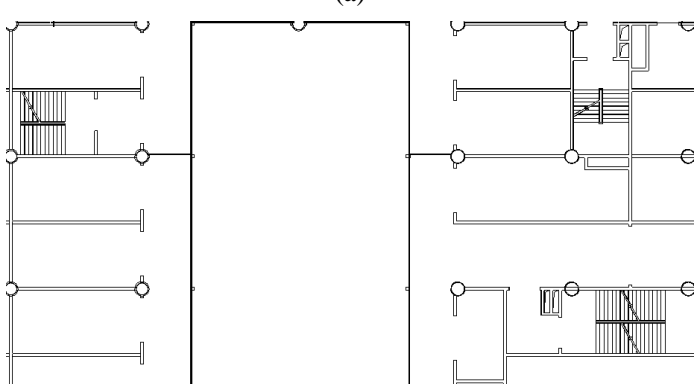

(b)

Figure 6. Detailed comparison before(a) and after(b) adding a stair exit

\section{Increasing Width of Evacuation Staircase}

For example, for the stair at position 3 in central business district, we can widen its width. In building EXODUS, we can easily deal with the problem by adding a arc to connect each stair door with neighboring nodes as shown in in Fig .7.

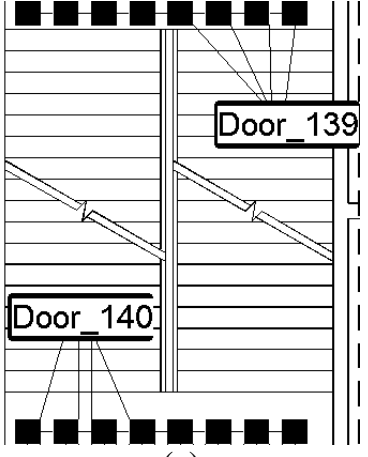

(a)

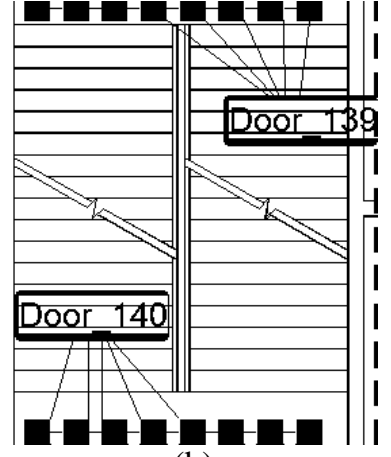

(b)
Figure 7. Detailed comparison before(a) and after(b) increasing width of the staircase

\section{CONCLUSIONS}

The Simulation results show that by adjusting the relative position of evacuation exit, adding an evacuation staircase and increasing the width of evacuation staircase, the time required for evacuation may be cut .Specific results are shown in table 2.

After modification, the total evacuation time is $218.2 \mathrm{~s}$ which is $24.1 \mathrm{~s}$ less than it before modification and reduces by nearly $10 \%$. The effect is relatively noticeable. Of course, there is still room for further optimization of the evacuation design of this building.

Using the above three kinds of optimization design methods can reduce the evacuation time to a certain extent. The methods have certain practical application value. By Comprehensive comparison, adjusting the relative position of evacuation exit has less effect on the evacuation time and increasing the number of emergency staircase is the most significant. But the two methods have a significant impact on the architectural structure.Considering the convenience, economy and normalization, increasing the evacuation width appropriately is the most feasible method. But this optimization design should be synchronized with architectural design. 
TABLE II. COMPARISON OF EVACUATION DATA BEFORE AND AFTER STAIR-MODIFICATION

\begin{tabular}{|c|c|c|c|c|c|c|}
\hline $\begin{array}{l}\text { Modified } \\
\text { Position }\end{array}$ & $\begin{array}{c}\text { Evacuation } \\
\text { Time before } \\
\text { Modification } \\
{[\text { [s] }}\end{array}$ & $\begin{array}{c}\text { Number of } \\
\text { Evacuees } \\
\text { before } \\
\text { Modification } \\
\text { [p] }\end{array}$ & Modifying Methods & $\begin{array}{c}\text { Evacuation Time } \\
\text { before Modification } \\
{[\mathbf{s}]}\end{array}$ & $\begin{array}{c}\text { Number of Evacuees } \\
\text { before Modification } \\
{[p]}\end{array}$ & $\begin{array}{c}\text { Optimization } \\
\text { Efficiency }\end{array}$ \\
\hline 1 & 220.59 & 1013 & $\begin{array}{l}\text { adjusting the relative position } \\
\text { of evacuation exit }\end{array}$ & 203.75 & 1008 & $7.63 \%$ \\
\hline 2 & 224.25 & 486 & adding an evacuation staircase & 150.42 & 565 & $32.92 \%$ \\
\hline \multirow{2}{*}{3} & $\begin{array}{l}117.34 \\
(139 \#)\end{array}$ & \multirow{2}{*}{682} & \multirow{2}{*}{$\begin{array}{l}\text { increasing the width of } \\
\text { evacuation staircase }\end{array}$} & 100.02 & \multirow{2}{*}{703} & $14.76 \%$ \\
\hline & $\begin{array}{l}213.95 \\
(140 \#) \\
\end{array}$ & & & 182.95 & & $14.49 \%$ \\
\hline
\end{tabular}

\section{ACKNOWLEDGMENT}

This paper is funded by the National Natural Science Funds (71173215) and the Jiangsu Province Natural Science Funds(BK2011217).

References

\section{REFERENCES}

[1] Zheng Y, Gao F G, Yao B H. Difficulties and countermeasures of personnel emergency evacuation in the city underground space taking Shanghai as an example. Shanghai Urban Management, 2013,(6),pp.22-25.

[2] Hao S Q. Study on evacuation during fire in underground space based on risk theory and EXODUS[J]. Chinese Journal of Underground Space and Engineering, 2010, 6(z1),pp.1495-1498.

[3] Yin M M. Research on the fire protection and evacuation of underground commercial space-taking underground commercial space in the underground traffic hub project at Tianjin cultural center as an example[J]. Chinese and Overseas Architecture, 2012, (8),pp.42-44.
[4] Wu X C, Xie D, Li L. An Analysis on the occupants evacuation time computation of the subway platform occupant[J]. Journal of Shenyang Institute of Aeronautical Engineering, 2012,29(5),pp.6873.

[5] Yu F. Thoughts on fire protection design of underground commercial space building[J]. Value Engineering, 2010,29(35), pp.72-72.

[6] Zhou T J, Yan Q, Zuo J. Analysis of sight and activity of safe escaping in underground commercial space-taking Chongqing underground commercial space as example[J]. DISASTER ADVANCES,2010,3(4),PP.157-162.

[7] Guo H L, Zhang L X. Study on safety evacuation of the city underground space in condition of fire[J]. Urbanism and Architecture,2013(14),pp.208-208.

[8] Shi H. Analysis of safety evacuation and fire protection design in underground space[J]. Low Carbon World,2013(6),pp.135-136.

[9] Code for Fire Protection Design of Buildings.GB50016-2006, pp.34-34.

[10] Fire Safety Engineering Group. Help for building EXODUS V4.0. University of Greenwich[R].UK, 2004,pp.2.1. 